\title{
MUUTAMIA HAVAINTOJA JUOLAVEHNÄN JUURAKOISTA JA JUURISTA.
}

\author{
Martti Salonen.
}

Suoviljelysyhdistys, Helsinki.

Saapunut 4. 4. 1949.

Tehdessäni kesällä 1948 tutkimuksia viljelyskasvien juurista (5) ilmeni pian, että rikkaruohojen juuret ovat sangen haitallisia. Niiden esiintymiskerros on sama kuin viljelyskasvien juurienkin ja niitä on sangen vaikea eroittaa toisistaan. Täyteen varmuuteen juuren laadusta pääsee useimmiten vasta, kun voi todeta, mistä kasvista se lähtee. Mikroskooppisesti on tosin mahdollista identifioida eri kasvien juuria (6), joskin sekin on vaikeaa ja toisinaan epävarmaa. Mainittakoon, että työssäni ei ollut mahdollisuuksia mikroskoopin käyttöön. Niinpä katsoin parhaaksi välttää rikkaruohoisia kohtia. Tämäkään ei aina onnistunut, sillä peltomaamme ovat aivan yleisesti rikkaruohojen vaivaamia. Erityisen paljon häiriötä oli juolavehnästä, joka osoittautui tavattoman yleiseksi. Juolavehnän vaivaamien kohtien toteaminen on avoviljelyksillä hyvin helppoa, mutta nurmilla ei niitä aina voi havaita päältäpäin. Kasvusto voi olla näköjään vapaa juolavehnästä, mutta kun tutkii maata, voi siinä olla runsaasti sen eläviä juurakoita ja juuria. - Yleensä ei juolavehnää pidetä nurmilla huomattavana rikkaruohona, koska se tuottaa käyttökelpoista rehua (7). Väitetään, että juolavehnä heikontuisi nurmessa (2, s. 530), mutta mitään siihen viittaavaa ei ole tekemissäni havainnoissa, sillä vanhemmissakin nurmissa olivat juurakot hyvin terveen ja elinvoimaisen näköisiä. On kuitenkin mahdollista, että ne nurmessa esiintyvät pinnallisempina kuin avoviljelyksessä (4, s. 483$)$.

Kun oli melkein mahdotonta välttää juolavehnää, tein senkin juuristoista muutamia havaintoja, ja lopuksi kaivoin muutaman havaintokuopan nimenomaan sen tutkimiseksi. Kun näillä havainnoilla voi olla yleisempääkin mielenkiintoa ja merkitystä, on ehkä paikallaan selostaa ne.

Havainnot on tehty pääasiassa kehittämälläni juurien eristysmenetelmällä (5), jolla saadaan kuva kaikista maassa esiintyvistä juurista $55 \mathrm{~cm}$ syvästä, $35 \mathrm{~cm}$ 
leveästä ja $10 \mathrm{~cm}$ paksusta maaleikkauksesta. Lisäksi tein täydentäviä havaintoja ns. suoralla menetelmällä, jossa juuret paljastetaan sitä varten tehdyn kuopan seinistä sopivalla aseella varovasti kaivaen.

1. $v: n$ nurmet.

\section{Juolavehnän juuristoista tehdyt havainnot.}

Suokoeasema Leteensuo, Hattula, 16/7. Mạa pitkälle maatunutta metsäsaraturvetta, hyvässä viljelyskunnossa, muokkauskerros $18 \mathrm{~cm}$. Pelkkä timoteinurmi, kasvu hyvä. Juolavehnää melkoisesti.

Juolavehnän juurakoiden sijainti maan pinnasta laskien välillä $0-10 \mathrm{~cm}$
$\longrightarrow$ juurien suurin syvyys
60 i)

Suokoeasema Suotalo, Tohmajärvi, 6/8. Maa löyhää hietaa, ns. vaaramoreenia, jossa tiivis kerros $60 \mathrm{~cm}$ syvyydessä, kohtalaisessa viljelyskunnossa, muokkauskerros $15-17 \mathrm{~cm}$. Apilatimoteinurmen kasvu kohtalainen. Juolavehnää paljon.
Juolavehnän juurakot $\quad 0-10 \mathrm{~cm}$ - - juurien suurin syvyys 60 "

Juuristosta otetusta tilavuusnäytteestä poistettiin muiden kasvien juuret, ja juolavehnän juurakoista sekä juurista tehtiin orgaanisen kuiva-aineen määritykset (5):

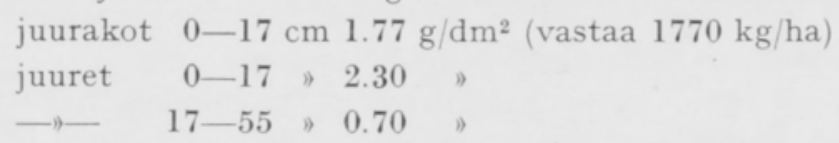

Pohjois-Savon koeasema Halola, Maaninka, 13/8 1. Maa löyhää hietaa, $75 \mathrm{~cm}$ syvyydessä tiivis hiesu, hyvässä viljelyskunnossa, muokkauskerros $22 \mathrm{~cm}$. Timotein siemenviljelys, kylvetty harvoin rivivälein, harattu keväällä, kasvu huononlainen. Juolavehnää paljon.
Juolavehnän juurakot
$5-15 \mathrm{~cm}$
- juurien suurin syvyys $\quad 75$ औ

Pohjois-Savon koeasema Halola, Maaninka 13/8 2. Maa kuten edellä. Timotein siemenviljelys, kylvetty tihein rivivälein, ei harattu, kasvu tyydyttävä. Juolavehnää melkoisesti.
Juolavehnän juurakot $\quad 5-10 \mathrm{~cm}$
$\longrightarrow$ - juurien suurin syvyys 80 "

\section{2. v:n nurmet.}

Pohjois-Hämeen koeasema Myttäälä, Pälkäne, 10/7. Maa löyhää hietaa, hyvässä viljelyskunnossa, muokkauskerros $22 \mathrm{~cm}$. Apilavaltaisen nurmen kasvu hyvä. Juolavehrää melkoisesti.
Juolavehnän juurakot $\quad 5-7 \mathrm{~cm}$
$\longrightarrow$ - juurien suurin syvyys 85 \#

Turun yliopiston tila Tuorla, Piikkiö 8/9. Maa urpasavea, multakerros $30 \mathrm{~cm}$, pohjavesi $83 \mathrm{~cm}$ syvyydessä. Kasvusto pelkkää juolavehnää.

Eläviä juolavehnän juurakoita välillä $0-10 \mathrm{~cm}$, syvemmällä muokkauskerroksessa runsaasti kuolleita, osittain hajaantuneita juurakoita, jotka ovat joutuneet sinne kynnössä. Syvimmät juuret $80 \mathrm{~cm}: s s a ̈$, harvassa, nopea lisääntyminen $60 \mathrm{~cm}$ :stä ylöspäin (kuva 1).

\section{3. $v:$ n nurmet.}

Yliopiston tila Malminkartano Helsingin kaupungin alueella, 29/6. Maa urpasavea, multa- = muokkauskerros $20 \mathrm{~cm}$. Timoteita ja varsinkin apilaa vähän jâ yksilöt huonokasvuisia. Juolavehnää hyvin paljon (kuva 2).

Juolavehnän juurakot

$$
0-10 \mathrm{~cm}
$$

$\longrightarrow$ juurien suurin syvyys $\quad 90$ \#

Juuristosta otetusta tilavuusnäytteestä poistettiin muiden kasvien juuret, ja juolavehnän juurakoista sekä juurista tehtiin org. kuiva-aineen määritykset: 


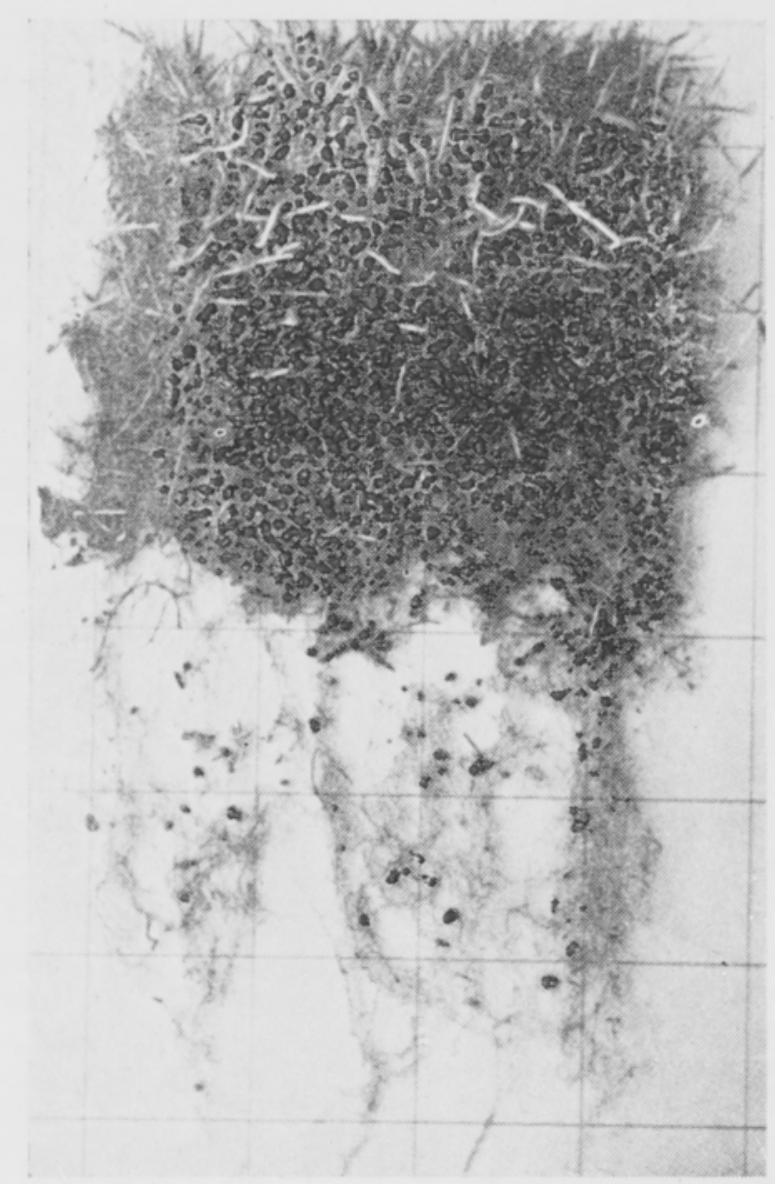

Kuva 1. Tuorla 8/9, 2. v:n nurmi, pelkkää juolavehnää. Koko muokkauskerroksessa runsaasti juurakoita, jotka ovat kuolleet $10 \mathrm{~cm}$ syvempänä. Juurien suurin syvyys $80 \mathrm{~cm}$. -

Viivojen välit ruudukossa $10 \mathrm{~cm}$.

Fig. I. Second year ley, sheer couch grass. Plenty of rhizomes throughout the furrow slice, those below the depth of Io $\mathrm{cm}$. are dead. The maximum depth of roots $80 \mathrm{~cm}$. - The lines in the screen Io cm. apart.

Valok. M. S.

\begin{tabular}{|c|c|c|c|c|}
\hline juurakot & $0-10$ & $\mathrm{~m}$ & & 4.90 \\
\hline juuret & $0-10$ & " & 3.23 & \\
\hline$\rightarrow-$ & $10-20$ & " & 1.53 & 4.76 \\
\hline-1$)$ & $20-55$ & ") & & 0.77 \\
\hline
\end{tabular}

Suokoeasema Suotalo, Tohmajärvi, 7/8. Maa löyhää hietaa, ns. vaaramoreenia, jossa kova, kivinen kerros $55 \mathrm{~cm}$ syvyydessä, muokkauskerros $19-20 \mathrm{~cm}$. Nurmen kasvu kohtalainen. Juolavehnää. paljon.

$\begin{array}{cr}\text { Juolavehnän juurakot } & 0-10 \mathrm{~cm} \\ - \text { - juurien suurin syvyys } & 65\end{array}$

\section{Havaintojen tarkastelua.}

Tehtyjen havaintojen mukaan juolavehnän juurakot sijaitsevat maassa ylimmässä $10 \mathrm{~cm}$ kerroksessa, lukuunottamatta yhtä tapausta, jossa niitä on ollut $15 \mathrm{~cm}$ syvässäkin. On mahdollista, että keväällä suoritetulla haraamisella on tässä vaikutusta. Juuret sensijaan menevät syvälle, suurimman syvyyden vaihdellessa välillä $60-90 \mathrm{~cm}$. Tämä on sama kuin useimpien viljelyskasvien juurten syvyys (5). 


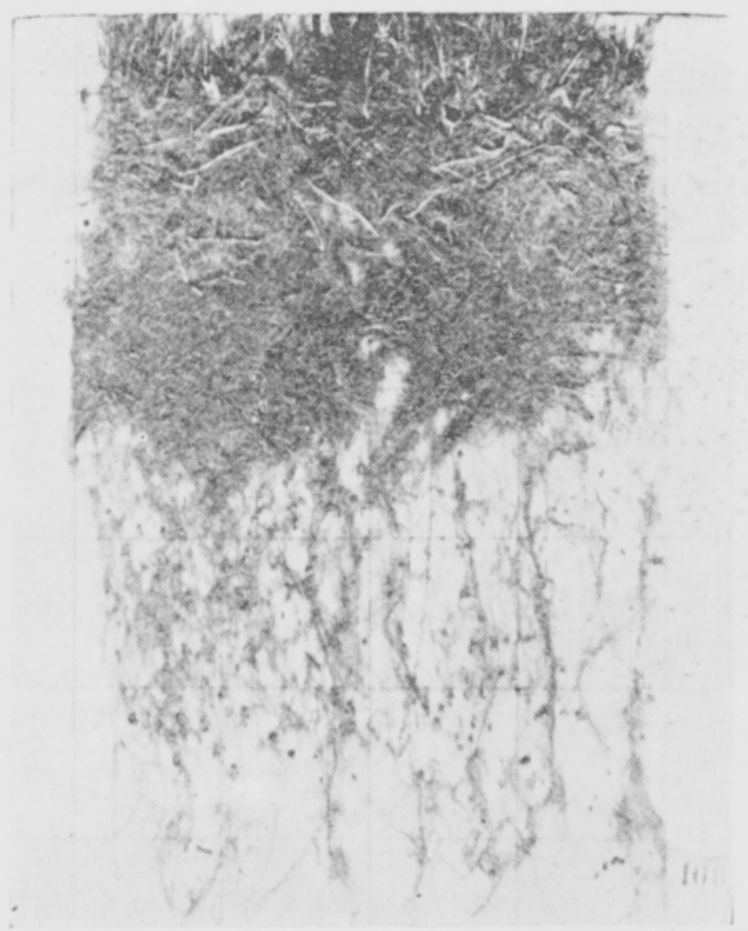

Kuva 2. Malminkartano 29/6. 3. v:n nurmi, runsaasti juolavehnää. Juurakoita vain $10 \mathrm{~cm}$ asti. Juurien suurin syvyys $90 \mathrm{~cm}$.

Fig. 2. Third year ley, plenty of couch grass. Rhizomes only to the depth of $\mathrm{IO} \mathrm{cm}$. The maximum depth of roots $90 \mathrm{~cm}$.

Valok. M. S.

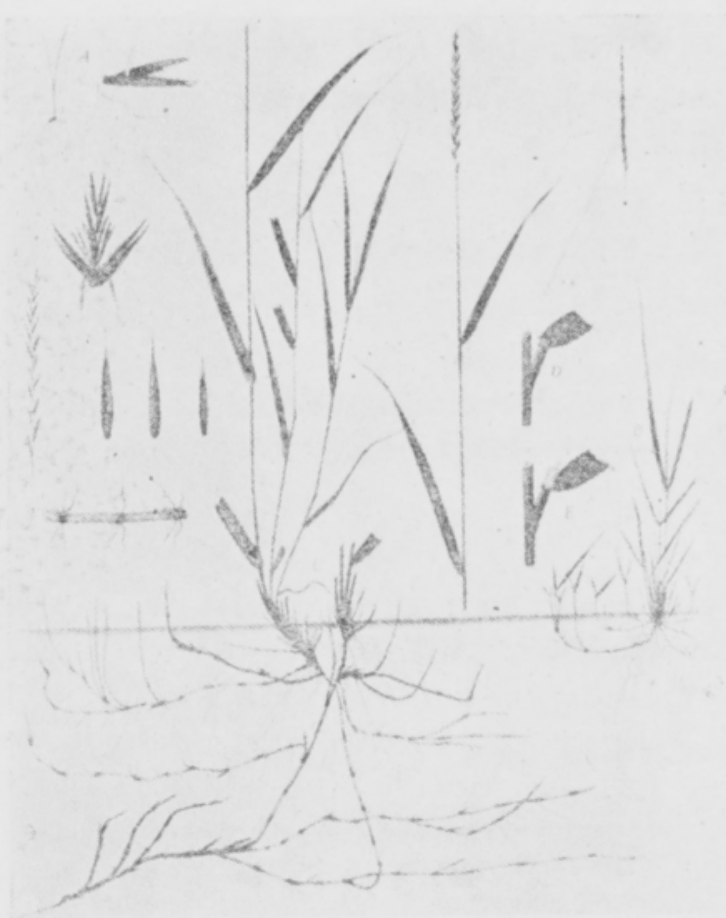

Kuva 3. Juolavehnän juuristo Korsmon mukaan. Huomaa vähäpätöiset juuret.

Fig. 3. The root system of couch grass according to Korsmo. Note the small roots.

TERÄsvuori (7) arvelee, että Suomessa juolavehnän juurakot ovat keskimäärin ylimmässä $10 \mathrm{~cm}$ kerroksessa. Sama lienee yleinen käsitys. Havainnot osoittavat sen oikeaksi, vieläpä viittaavat siihen, että juurakot kuolevat, jos joutuvat syvemmälle maahan.

Kirjallisuudessa en ole tavannut mainintoja juolavehnän juurien syvyydestä. Korsmon (2, s. 475) julkaisemien kuvien perusteella saa sellaisen käsityksen, että juolavehnän juuret ovat aivan lyhyet (kuva 3). Saman käsityksen esittää HıLli (1). Tässä esitetyt havainnot osoittavat kuitenkin, että juolavehnä on syväjuurinen kasvi, ja juurien lukumäärä on hyvin suuri. Virheellinen käsitys juolavehnän juurista johtunee siitä, että pitemmät juuret katkeavat hyvin helposti tyvestä, jos juurakko kiskaistaan varomattomasti maasta. Siihen jää vain lyhyitä juuria, jolloin helposti muodostuu sellainen luulo, ettei muunlaisia olekaan. Mainittakoon tässä yhteydessä, että WEAvER (8, s. 120) on julkaissut kuvan juolavehnän amerikkalaisen sukulaisen Agropyron Smithiin juuristosta, josta ilmenee, että sen juuret voivat mennä jopa 8 jalkaa $(=244 \mathrm{~cm})$ syvälle.

\section{Juolavehnän hävittämisestä.}

Juolavehnä on epäilemättä pahimpia rikkaruohojamme, jonka esiintyminen suuresti vaikeuttaa kunnollista viljelystä. Se leviää ja lisääntyy paitsi siemenistä (2 ja 7) myös suuressa määrässä nopeasti kasvavista juurakoista. Pelkät juuret 
sensijaan eivät voine kehittää uusia versoja. Juurakoiden tuhoamiseksi käytetään yleensä niiden tukehduttamista joko usein toistetuilla muokkauksilla (kesanto, vakoharjakesanto) tai tiheällä ja rehevällä viljelyskasvilla (jokin palkokasvi, $2 \mathrm{~s}$. 478,3 s. 194) tai molempien vaikutusten yhdistämisellä (peruna).

Havainto, että juurakot eivät ainakaan nurmessa pysy hengissä $10 \mathrm{~cm}$ (joskus $15 \mathrm{~cm})$ syvemmällä maassa, herättää kysymyksen, eikö kynnöllä voitaisi haudata juurakoita riittävän syvälle ja siten nopeasti päästä ikävästä rikkaruohosta. Kyntö olisi ilmeisesti tehtävä sellaiseen aikaan, että elävät juurakot rajoittuvat vain tuohon suhteellisen ohueen kerrokseen (esim. nurmen jälkeen), ja todella niin syvään, ettei juurakoita joudu $10 \mathrm{~cm}$ lähemmäksi pintaa. Kyntö olisi myös tehtävä siten, että viilu kaatuu lappeelleen eikä jää syrjälleen kuten tavallisessa kynnössä. Silloin viilun on oltava verraten leveä, leveyden ja paksuuden suhde suurempi kuin 1.4: 1 . Kynnön jälkeen tehtävillä äestyksillä ei saa vetää juurakoita pintaan. Tällaisen menetelmän käyttömahdollisuuksia rajoittaa suuresti, että meillä vanhan kokemuksen mukaan useimmilla mailla on vahingollista kääntää "raakaa" pohjamaata pintaan. Tarvittavan kyntösyvyyden (n. $25 \mathrm{~cm}$ ) vuoksi tällainen kyntö on myös vaikea suorittaa, mutta käyttämällä traktoria ja kookasta ruuvisiipiauraa pitäisi sen olla mahdollista. Ainakin voitaisiin menetelmää kokeilla pienilla aloilla.

\section{Yhteenveto.}

Juolavehnän juurakoiden ja juurien sijainnista maassa on tehty muutamia havaintoja eri ikäisillä nurmilla. Niiden mukaan juurakoita yleensä esiintyy vain n. $10 \mathrm{~cm}$ paksussa kerroksessa maan pinnalla. Vain yhdessä tapauksessa todettiin niitä $15 \mathrm{~cm}$ syvyydessä. Juurakoista lähtee hyvin paljon ja syvälle meneviä juuria, joiden suurin syvyys on vaihdellut $60-90 \mathrm{~cm}$ välillä. Myös on tehty havaintoja, joiden mukaan juurakot kuolevat, jos joutuvat $10 \mathrm{~cm}$ syvemmälle maahan. Havainnon soveltamismahdollisuuksia juolavehnän hävittämiseen on tarkasteltu. 


\section{KIR JALLISUUTTA.}

(1) Hilli, A. 1949. Juolavehnän torjuntamenetelmistä. Koetoiminta ja käytäntö, 6, vihko $1-2$, s. 2.

(2) Korsmo, E. 1925. Ugress i nutidens jordbruk. Oslo.

(3) Krause, M. 1928. Steigerung der Ernteerträge durch verbesserte Bodenbearbeitung. Berlin.

(4) Robbins, W. W., A. S. Crafts and R. N. Raynor 1942. Weed control. New York.

(5) Salonen, M. 1949. Tutkimuksia viljelyskasvien juurten sijainnista Suomen maalajeissa. Acta Agr. Fennica, 70,1.

(6) SchröDER, D. 1926. Unterscheidungsmerkmale der Wurzeln unserer Wiesen- und Weidenpflanzen. Landw. Jahrb., 64, s. 41-64.

(7) Teräsvuori, K. 1929. Die Quecke, Triticum repens L., als Kulturpflanze und Unkraut. Acta Agr. Fennica 18 , s. $33-58$.

(8) Weaver, J. E. 1926. Root development of field crops. New York.

\section{SUMMARY:}

SOME OBSERVATIONS ABOUT THE RHIZOMES AND ROOTS OF COUCH GRASS

$$
\text { [Agropyron repens (L.) PB.] }
$$

By Martti Salonen.

The Peat Culture Society of Finland, Helsinki.

In summer 1948, when making observations about the root relations of field crops (5), I acquired as by-product some data about the rhizomes and roots of couch grass, which is one of the most common and most detrimental weeds under the conditions in Finland. The method employed in these observations (5) made it possible to acquire a clear picture about the position of the rhizomes and roots, about their extent and about the depht of the roots. As we have not sufficient information about these things (2), I thought it desirable to publish the obtained facts, scarce as my observations are.

The rhizomes of couch grass are confined to a very thin surface layer in the furrow slice, the maximum depth being usually $10 \mathrm{~cm}$. Only in one of the cases I examined the maximum depth was $15 \mathrm{~cm}$. Possibly a very airy soil and cultivation in spring contributed to this case. Some facts seem to indicate that rhizomes die, if they are deeper in the soil than $10 \mathrm{~cm}$. In general couch grass is considered a very shallow-rooted plant (fig. 3, a quotation from Korsmo, 2), but my observations show that the root system of couch grass is very profuse and penetrates deep into the soil, the maximum depth being $60-90 \mathrm{~cm}$., which is the same as the maximum depth of the roots of field crops. 